\title{
EDUCAÇÃO PARA A SAÚDE NA TERCEIRA IDADE: relato de experiência ${ }^{1}$
}

\author{
Emiliane Nogueira de Souza ${ }^{2}$ \\ Salete Bagiotto Lago ${ }^{2}$
}

\section{Resumo}

Este trabalho descreve as atividades desenvolvidas durante o estágio supervisionado da disciplina Prática de Ensino do Curso Licenciatura em Enfermagem da UFRGS, o qual objetivou discutir questões relativas à saúde na terceira idade, visando a promoção de uma melhor qualidade de vida. Durante os encontros foram discutidos diferentes temas, definidos previamente em conjunto com os participantes, que fazem parte do Programa do Idoso implementado pela Secretaria Municipal de Saúde de Viamão, o qual beneficia pessoas com mais de 60 anos e renda mensal de até um salário mínimo. A metodologia utilizada foi diversificada, em função da escolaridade e interesses dessas pessoas. Destaca-se alguns aspectos considerados relevantes: convívio grupal e auto-estima, momentos de aprendizagem, entendimento sobre as modificações naturais do processo de envelhecimento e a integração profissional-comunidade.

Palavras-chave: Saúde; Educação; Qualidade de Vida; Idosos; Enfermagem.

\begin{abstract}
This paper describes the activities developed during the supervised training course of Prática de Ensino (Pacticum), which is part of the Escola de Enfermagem program in the Universidade Federal do Rio Grande do Sul (UFRGS). Such training course was meant to discuss issues related to health in old age aiming at promoting better quality of

\footnotetext{
1 Trabalho realizado na disciplina EDU 02006 Prática de Ensino em Educação e Saúde, do Curso de Licenciatura em Enfermagem da Universidade Federal do Rio Grande do Sul, sob orientação e supervisão da $\operatorname{Prof}^{\mathrm{a}} \operatorname{Dr}^{\mathrm{a}}$ Dagmar Estermann Meyer

${ }^{2}$ Enfermeiras do Instituto de Cardiologia do Rio Grande do Sul, alunas do curso de Licenciatura em Enfermagem da UFRGS. E-mail: enogsouza@hotmail.com
} 
life. Different topics, previously defined along with the participants were discussed during the meetings. The participants belong to the "Programa do Idoso" (Ederly Program), implemented by the Secretaria Municipal de Saúde de Viamão (RS - Brazil) which serves people who are over 60 years old and who earn minimum wage. Diverse methodology was used and depended on people's interests and level of education. Relevant aspects are: group association and self-esteem; learning moments; understanding the natural modifications during the aging process; professional-community integration.

Keywords: Health; Education; Life Quality; Senior Citizens; Nursing.

\section{Introdução}

As questões relativas ao envelhecimento da população vêm adquirindo relevância em função do desenvolvimento econômico e do crescente número de pessoas com mais de 60 anos no Brasil. Embora a velhice tenha merecido a atenção dos poderes públicos, as políticas sociais brasileiras e o interesse nesta temática vêm crescendo de maneira incipiente. $\mathrm{O}$ aumento da faixa etária populacional constituiu-se num problema social, sobretudo em função das consequiências econômicas, que afetou as estruturas capitalistas e, posteriormente, o Estado, com o advento das aposentadorias (PEIXOTO, 1998).

O envelhecimento é um processo multidimensional, ou seja, depende de todas as vivências anteriores do indivíduo, desde sua infância até a maturidade, tanto sob o ponto de vista biológico quanto sócioemocional e econômico. Essas vivências irão influir na capacidade de enfrentamento das modificações que ocorrem com o aumento da idade, traduzindo-se em diferentes modelos de velhice (RODRIGUES, 2000).

Um estudo realizado por Peixoto (1998) quanto à terminologia utilizada para denominar essa parte da população, mostra que até os anos 60, as pessoas pertencentes a esta faixa etária eram simplesmente velhas. O termo velho podia ou não estar carregado de conotações negativas, mas quando isso acontecia era empregado para reforçar uma situação de exclusão social. No final da década de 60, a mudança de imagem da velhice na Europa, principalmente, na França, influenciou as instituições governamentais brasileiras na utilização da nomenclatura 
para designar pessoas envelhecidas. Assim, o termo idoso simboliza as pessoas mais velhas e respeitadas, enquanto terceira idade ${ }^{3}$ designa os "jovens velhos", os aposentados dinâmicos, passando a ser a expressão classificatória de uma categoria social bastante heterogênea etária e economicamente.

Ao mesmo tempo em que se verifica um aumento significativo na expectativa de vida dos brasileiros, uma pesquisa realizada no Rio Grande do Sul, em 1997, revela que 49,08\% dos idosos apresentam uma renda em torno de dois salários mínimos e, 10,41\% não possuem nenhuma renda, sendo que a concentração de gastos desta população está na alimentação e na aquisição de remédios (RIO GRANDE DO SUL, 1997). Esses dados apontam, portanto, para uma situação econômica precária de boa parte da população idosa e que também apresenta saúde debilitada.

Essa situação, não é diferente no município de Viamão - região metropolitana de Porto Alegre - onde está em fase de implementação o Programa do Idoso, no qual a maioria da população assistida encontrase na faixa etária de 70 a 75 anos, é analfabeta e apresenta renda familiar em torno de um salário mínimo. No contexto desse programa, a Secretaria de Saúde e o Departamento de Cidadania e Assistência Social do município firmou uma parceria com a Universidade Federal do Rio Grande do Sul (UFRGS), com o objetivo de trabalhar a promoção da saúde e a prevenção de doenças mais comuns à terceira idade através de processos educativos desenvolvidos junto ao idoso e a sua comunidade, considerando-se suas expectativas, valores e necessidades e resgatando sua condição de cidadão.

Grande parte da população idosa tem em comum a experiência de vivenciar, em pelo menos uma dimensão, o processo de exclusão social e, diante desse processo é que se formam grupos de terceira idade, os quais têm sido porta-vozes das necessidades e aspirações de tal segmento. Os grupos de terceira idade carregam consigo um potencial de transformação do cotidiano, para ampliar e consolidar o ideal de democracia (PORTELLA, 2001), bem como promover um melhor aproveitamento

\footnotetext{
3 Terceira idade: termo utilizado pela Organização das Nações Unidas (ONU) relativo à divisão do ciclo da vida, sob o ponto de vista econômico, para aquelas pessoas que já produziram e consumiram mas que, pela aposentadoria, não produzem mais, só consomem, portanto idade inativa (RODRIGUES, 2000). A ONU estipulou ainda, para considerar $3^{\mathrm{a}}$ idade, os 60 anos para países subdesenvolvidos ou em desenvolvimento e 65 anos para os países desenvolvidos.
} 
do tempo que lhes resta de maneira saudável, independente e com o máximo de autonomia (BENEDETTI, 2001).

Este trabalho foi desenvolvido na disciplina Prática de Ensino em Educação em Saúde, ministrada no Curso de Licenciatura em Enfermagem, como atividade de estágio docente, no segundo semestre de 2000. Como enfermeiras, alunas da licenciatura e coordenadoras desse trabalho no grupo de idosos discutimos, durante os encontros semanais, temas relacionados à educação em saúde, visando à promoção do autocuidado para uma melhor qualidade de vida. Bem sabemos que as alterações que ocorrem com o processo de envelhecimento interferem diretamente no cotidiano do indivíduo, exigindo adaptações e modificações nos hábitos de vida individuais e coletivos. E para que essa adaptação ocorra, é necessária a orientação para uma vida mais saudável.

Com base nos artigos $3^{\circ}$ e $4^{\circ}$ da Política Nacional do Idoso, regulamentada pelo Decreto ${ }^{\circ} 1.948$ de 3 de julho de 1996, são delimitados alguns pressupostos norteadores do trabalho educativo que desenvolvemos, quais sejam:

- No processo de envelhecimento ocorrem modificações de ordem biopsicossocial que se dão através de perdas ou ganhos, influenciando as relações com o meio;

- O exercício da cidadania é garantido ao idoso por meio da sua participação na comunidade através de diferentes programas, assegurados em lei, tendo direitos e deveres para com ele mesmo, para com a família e a sociedade;

- O aprendizado se dá em todas as fases da vida. Daí a necessidade de se partir para novas aprendizagens, evitando que o envelhecimento provoque a estagnação intelectual, recaindo na rotina e marginalização social;

- A educação em saúde promove a expansão das práticas de saúde junto à comunidade, como uma forma de desenvolver na população uma postura crítica quanto à saúde e quanto à vida em geral.

Em consonância com tais pressupostos, fixamos dois princípios que deveriam dar sustentação ao nosso trabalho pedagógico:

- Procurar otimizar as formas alternativas de participação, convívio e ocupação do idoso, integrando-o aos diferentes segmentos da sociedade; 
- Levar em consideração as necessidades e interesses do idoso, bem como suas experiências e conhecimentos prévios, a fim de que saia da condição de mero espectador das atividades propostas e se torne sujeito das mesmas.

Enquanto enfermeiras envolvidas com a educação em saúde, acreditamos que precisamos estar capacitadas para intervir no processo saúde - doença pela problematização das Políticas Públicas e pela proposição de ações baseadas no saber técnico-científico, que tenham o potencial de envolver a população na busca de alternativas para viver de forma mais saudável (DILLY, 1995).

\section{Caracterização do Grupo e o Planejamento Participativo}

Em um primeiro momento, quando conhecemos o grupo de idosos através do Programa do Idoso, que os reúne mensalmente para a entrega de cestas básicas, foi lhes apresentada a proposta de trabalho que envolvia a Secretaria Municipal de Saúde e a Faculdade de Educação da UFRGS. Marcamos um encontro com eles para que pudéssemos nos reunir e melhor conhecê-los, levantando alguns dados que se tornaram importantes para encaminhar o planejamento do Projeto de Ensino que deveríamos desenvolver. Realizamos um levantamento sobre suas necessidades e interesses, de maneira mais dinâmica e participativa num segundo momento, pois observamos que no primeiro encontro, os participantes tiveram um pouco de dificuldade para se manifestar sobre as questões postas.

Assim, reunimos os idosos em grupos de quatro e cinco pessoas num total de treze participantes, dos quais apenas um era do sexo masculino. Entregamos materiais para que desenhassem com quem moravam e posteriormente, recortassem de revistas o que lhes chamou mais atenção para ser colado juntamente com o desenho. Enquanto os idosos realizavam a atividade proposta, aplicamos um questionário individual, com o objetivo de levantar informações que possibilitassem uma melhor caracterização do grupo e, a partir de então, pudéssemos planejar em conjunto os temas/atividades a serem trabalhados, o que chamamos de planejamento participativo.

Após o término da atividade, realizamos um círculo, onde cada um expôs e comentou seu trabalho. Os participantes do grupo ficaram 
surpresos com suas criações, pois muitos não tinham o hábito de desenvolver atividades que envolvem desenhar e colar. Isso se deve ao fato de que a maioria não freqüentou a escola (69\% são analfabetos). Todos estavam na faixa etária dos 70 aos 80 anos e o estado civil predominante foi viúvo (61\%).

Observamos pelos relatos que são pessoas adaptadas à realidade na qual estão inseridos, dizendo estarem satisfeitos com o que fazem (cuidar da casa e dos netos $-61 \%$ ). A maioria relatou algum tipo de doença, sendo que a hipertensão arterial apareceu com maior frequiência (46\%), seguida por problemas gástricos (30\%) e reumatismo (23\%); apenas quatro pessoas (30\%) participavam de outra atividade associativa ou de grupo.

Quando perguntados sobre as vantagens e desvantagens da terceira idade, apareceram mais as desvantagens: perda de familiares, limitações físicas (visuais, auditivas e de locomoção), doença do(a) companheiro(a), distância da família, influência das intempéries e sedentarismo. Em contrapartida, o tempo livre, a convivência com netos e bisnetos e o carinho dos filhos constituem as principais vantagens.

De posse dessas informações, planejamos os temas dos cinco encontros que deveriam integrar nosso projeto de trabalho.

\section{Os Encontros e a Promoção da Educação para a Saúde}

Semanalmente, durante dois meses, o grupo se reuniu no salão de festas de uma instituição particular de Viamão, a qual cedeu o espaço para os encontros. Em cada um destes encontros desenvolvemos um tema específico: auto-estima e o processo de envelhecimento; hábitos alimentares; plantas medicinais e sua utilização; programas de assistência ao idoso oferecidos pelo município; atividade física e cuidados com a medicação. Assumimos a função de mediadoras dessa prática educativa e, desse lugar, procurávamos criar um ambiente onde todos se sentissem à vontade para participar, sempre expondo o tema e a metodologia a ser utilizada no decorrer do encontro.

Observamos que as pessoas de classes populares, com o desgaste do trabalho, iniciado muitas vezes na infância, envelhecem mais cedo. Há baixa longevidade, saúde debilitada, baixos rendimentos nas pen- 
sões e aposentadorias, escolaridade precária, enfim, fatores que os posicionam em situações de desvantagem social e que os levam a um maior desgaste físico e mental. Nesse sentido, a didática desenvolvida por nós buscou contemplar os interesses e o modo de vida destas pessoas, o que exigiu maior criatividade e sensibilidade. Propusemos atividades que integravam o lazer à aprendizagem, enfatizamos dinâmicas de grupo e a utilização de material visual: atividades práticas em detrimento da escrita e leitura.

Rodrigues (2000) menciona que na educação para idosos, mais importante que o conteúdo em si é despertar a capacidade de confiança em si mesmo, sua autonomia e problematizar os estereótipos que poderão estar influindo negativamente em sua vida. Em consonância com o que propõe a autora, procurou-se, através de discussões coletivas, despertar uma participação mais ativa, valorizando as experiências pessoais e suas particularidades. Um outro tipo de metodologia utilizada foi as dinâmicas de grupo - atividades lúdicas adaptadas aos idosos - de caráter educativo, as quais oportunizaram ao grupo momentos de alegria e de descontração. Ainda sobre a metodologia desenvolvida, pode ser salientada que a realização de atividades práticas como atos culinários relacionados à alimentação saudável e às plantas medicinais e os alongamentos referentes às atividades físicas, caracterizaram-se como oportunidades para resgatar a consciência preventiva quanto às doenças e terapia medicamentosa.

A temática relacionada à assistência de saúde ao idoso, oferecida pelo município, tornou-se igualmente importante, pois a maioria dos participantes desconhecia a existência de programas para a terceira idade, bem como alguns de seus direitos. Nesse encontro, pode-se discutir a municipalização da saúde e, com isso, esclarecer as etapas do processo de assistência à saúde da população idosa naquele município.

\section{Considerações Finais}

Uma das principais preocupações das pessoas idosas, atualmente, é com sua saúde, ainda mais quando a falta dela impõe restrições ao bem-estar. Não é possível curar alguém do envelhecimento que, além de fazer parte de vida, manifesta-se de formas variadas e com cronologias 
diferentes em cada indivíduo. Pode-se, entretanto, tomar diversas medidas a fim de evitar ou retardar o aparecimento de doenças e assim acrescentar vida aos anos e não apenas anos à vida (GROISMAN,1999).

Dessa forma, acreditamos que os profissionais da área da saúde, comprometidos com as questões educativas, devem ser capazes de socializar o seu conhecimento e, com isso, intervir qualitativamente nos padrões de saúde individual e coletiva, que envolvem não só hábitos e comportamentos, mas condições gerais de vida. Buscar a "ação participativa” (GASTALDO, 1997), a qual incentiva a participação comunitária, entendida como uma parceria entre profissionais e usuários, em que estes falam de si e de seu modo de vida, contribuindo para a discussão de problemas identificados conjuntamente, colaboram para a implementação de ações planejadas em, e para, grupos ou indivíduos na comunidade e avaliam os resultados dessa implementação.

\section{Referências}

1 BENEDETTI, T. B. Exercício Físico e Atividades da Vida Diária em Idosos Asilados. Texto \& Contexto Enfermagem, Florianópolis, v. 10, n. 2, p. 196202, maio/ago., 2001.

2 BRASIL. Lei no 8.842 de 04 de janeiro de 1994. Política Nacional do Idoso. Disponível em: <http:// saúde.gov.br/programas/idoso/política.htm>. Acesso em: 15 set. 2000.

3 DILLY, C. M. Processo Educativo em Enfermagem. São Paulo: Probel Editorial, 1995.

4 GASTALDO, D. É a Educação em Saúde Saudável? Educação e Realidade, Porto Alegre, v. 22, n. 1, p. 147-168, jan./jun. 1997.

5 GROISMAN, D. Asilos de Velhos: passado e presente. Estudos Interdisciplinares sobre o Idoso, Porto Alegre, v. 2, p. 67-87, 1999.

6 PEIXOTO, C. Entre o estigma e a compaixão e os termos classificatórios: velho, velhote, idoso, terceira idade... In: BARROS, M. L. (Org.). Velhice ou Terceira Idade? estudos antropológicos sobre identidade, memória e política. Rio de Janeiro: Fundação Getúlio Vargas, 1998. p. 69-84.

7 PORTELLA, M. R. A Utopia do Envelhecer Saudável nas Ações Coletivas dos Grupos da Terceira Idade: canais de aprendizagem para a construção da cidadania. Texto \& Contexto Enfermagem, Florianópolis, v. 10, n. 2, p. 196202, maio/ago., 2001. 
8 RIO GRANDE DO SUL. Conselho Estadual do Idoso. Os Idosos do Rio Grande do Sul: estudo multidimensional de suas condições de vida. Relatório de pesquisa. Porto Alegre: CEI, 1997.

9 RODRIGUES, N. C. Envelhecimento e Cidadania. In: SCHONS, C. R.; PALMA, L. T. S. (Org.). Conversando com Nara Costa Rodrigues sobre Gerontologia Social. Passo Fundo: UPF Editora, 2000. p. 77-81. 